\title{
Going out, getting about: atmospheres of mobility in Melbourne's night-time economy
}

Cameron Duff and David Moore, National Drug Research Institute - Melbourne

Office, Faculty of Health Sciences, Curtin University, Fitzroy, Australia

\begin{abstract}
Drawing from recent affective geographies of drinking and drunkenness, this article explores the affective atmospheres of spaces of mobility in Melbourne's night-time economy and how these atmospheres shape the experience of alcohol related problems. Our discussion is grounded in the analysis of interview data collected in 2012 among 60 young adults living in Melbourne. Participants included youth residing in the inner-city who reported taking a tram, walking or cycling to nearby venues along with youth from periurban communities who used trains, buses or taxis to travel to and from venues in the inner city. Each group reported spending varying amounts of time on the move during a night out drinking, although the atmospherics of mobility differed for each group. Inner-city participants described "comfortable" or "fun" journeys on the tram, walking or cycling, whereas participants from periurban communities spoke of "boring" or "unpleasant" journeys via train, night-bus or taxi. Moving beyond reports of the 'priming' effects of affective atmospheres, we conclude that these atmospheres are (co)constituted in encounters between bodies, human and nonhuman, as they move. We close with a brief discussion of the implications of our analysis for the study of alcohol related problems in the city at night.
\end{abstract}

\section{Keywords}

mobilities, affective atmospheres, alcohol, night-time economy, youth, Melbourne. 
The promotion and consumption of alcohol is central to the enduring appeal of spaces of leisure and sociality in the city at night (Shaw, 2014). Alcohol is just as often implicated in discussions of health and social problems in this night-time economy (NTE) (Jayne, Valentine \& Holloway, 2008). While early enthusiasm for the NTE emphasised its role in revitalising inner-city economies (Hubbard, 2007), this enthusiasm has been tempered by studies describing a significant increase in alcohol related problems in the city at night (Babor et al., 2010). These problems are commonly attributed to the liberalisation of liquor licensing arrangements - such as the extension of trading hours and an increase in the number and density of licenced venues - widely introduced to stimulate growth in the NTE (Jayne et al., 2008). As a result, the design of strategies for reducing alcohol related problems in the NTE has become a focus of research and policy development in law enforcement, public health, urban planning, transport and related fields (Roberts and Eldridge, 2009). Much of this work focuses on the spaces of the NTE, including licensed venues and entertainment precincts, and the distribution of alcohol related problems in these spaces. Human geographers have made important contributions to this research, offering assessments of the spatial and temporal features of alcohol consumption in the city at night (see Jayne, Valentine \& Holloway, 2011 for a review). Key findings include evidence of a link between outlet density, the design of venues, and the incidence of alcohol related problems including violence, accidents and injuries (Roberts, 2006). Other scholars have investigated attitudes regarding venues or settings in the NTE, and how consumer preferences shape the use (and misuse) of alcohol in these spaces (Eldridge \& Roberts, 2008). More recently, geographers have explored the affective and embodied dimensions of alcohol consumption in the NTE in order to capture more of the lived experience of drinking in the city at night (Jayne, Valentine \& Holloway, 2010; Shaw, 2014). Often absent from this research has been consideration of spaces of mobility in the NTE, despite widespread interest among human geographers in the 'new mobilities paradigm' (Cresswell, 2010).

The paper proceeds from the conviction that spaces of mobility are a key feature of the NTE both in terms of the routes and means by which individuals move between settings in the NTE, and by dint of the time spent in transit on a night out drinking. Drawing from recent affective and embodied geographies of drinking (Jayne et al., 2010), we wish to examine the "affective atmospheres" (Anderson, 2009) of select 
spaces of "mundane mobility" (Binnie, et al., 2007), and how these atmospheres shape the experience of drinking in the city at night. By drawing together analyses of mobilities and affective atmospheres we aim to further clarify the embodied and performative aspects of drinking in the city at night (Jayne et al., 2010). Mark Jayne, Gill Valentine and Sarah Holloway (2010, p. 552) argue that such a focus ought to avail "more nuanced and sophisticated" approaches to reducing alcohol related problems in the NTE. At issue is the need to understand the affective appeal of the NTE, and the embodied pleasures of a night out drinking more directly, such that strategies more sensitive to the diverse social contexts that frame alcohol consumption in the NTE might be devised (see Shaw, 2014, p. 93-4). In exploring these issues, we ground our discussion in the analysis of interview data collected among 60 young adults living in Melbourne, Australia. Participants included youth residing in the inner-city who mainly reported taking a tram, walking or cycling to licensed venues close to their homes, along with youth from periurban communities who typically used trains, buses and/or taxis to travel to and from venues in the inner-city. Each group reported spending varying amounts of time on the move on a night out drinking, although the atmospherics of mobility differed significantly for each group. Inner-city participants spoke of "comfortable", "direct" or "fun" routes on the tram, walking or cycling, whereas participants from periurban communities spoke of "boring", "scary", "frustrating" or "unpleasant" journeys via train, night-bus or taxi.

Along with David Bissell (2010, p. 273-75) we argue that these divergent affective atmospheres "prime" individuals to act in certain ways, having direct and indirect impacts on alcohol related problems in the NTE. The more congenial atmospheres described by inner-city participants seemed to mitigate the likelihood of problems, whereas the atmospheres of boredom, frustration and fatigue described by periurban participants appeared to increase the potential for harm. However, our analysis also suggests the need for closer attention to the ways affective atmospheres are coconstituted in the relations and events that shape encounters between bodies, human and nonhuman, as they move. Our findings highlight the ways affective atmospheres are enacted and transformed in encounters in (and through) spaces of mobility. We start by reviewing recent accounts of mobility and affective atmospheres before introducing the results of our study. We close by discussing the implications of our study for analyses of alcohol related problems in the city at night. 


\section{Space and Mobility in the Night-time Economy}

Our analysis integrates two significant strands of contemporary research in human geography that are rarely connected in analyses of the NTE (see Jayne et al., 2012 for an exception). We first examine studies of mobility, and the practices, modes and spaces it enacts (Cresswell, 2010), before considering the production and significance of affective atmospheres (Anderson, 2009) in the NTE. Tim Cresswell's (2010) influential analysis of mobility provides our starting point. Cresswell (2010, p. 19) argues that all mobilities, including walking, driving, migration and trade, comprise three constitutive features: movement, representation and practice. Movement is the "raw material for the production of mobility", yet this says little about what "mobilities are made to mean or how they are practised" (Cresswell, 2010, p. 19). There is always more to mobility than the simple act of movement, insofar as all mobilities inevitably take on contingent meanings. From the glamour associated with certain forms of air travel, to the tedium ascribed to the daily commute, or the threats imagined in the movements of refugee populations, all mobilities find meaning in the representations made of them. The meaning of mobility is further inflected in practice, in the ways bodies, objects or ideas move, and the things that happen to them as they move. Citing the example of walking, Cresswell (2010, p. 20) notes that walking is an "embodied and habitualised" practice that differs profoundly from body to body (see also Duff, 2010). Understanding mobility requires attention to the practices by which movement is expressed, repeated and transformed, and the ways these practices are "encoded culturally and socially" (Cresswell, 2010, p. 20)

Cresswell (2010, p. 22-26) next identifies six "aspects of moving" (motive force, speed, rhythm, route, experience and friction) that for our purposes suggest the basis for novel empirical analyses of mobility in the NTE. Motive force asks after why a person or thing moves, and whether that person or thing chooses or is compelled to move. Choice and compulsion speak to the kinds of meanings that may be associated with mobility. Next, the velocity of movement - and the forces that either enhance or mitigate this speed - is central to the experience of mobility and the "hierarchies" that shape it (Cresswell, 2010, p. 23). For example, the capacity to move quickly is typically taken as an indication of privilege, while interruptions in the pace of movement often accord with lower status. The third feature of mobility is rhythm. Rhythm describes the relative passages of movement and rest (speed and 
slowness) that characterise mobilities and their repetitions. The rhythm of the daily commute with its patterns of movement and rest, dictated by the order of timetables, schedules and traffic flows, provides an obvious example of this aspect of mobility.

Yet the daily commute is also shaped by predictable, regular routes. All mobility follows a route, although the ways routes are laid out in organised schedules, networks or channels betrays something of the value ascribed to different forms of mobility. An example may be the difference between modern, fast toll roads that connect various parts of the city, and older public transit routes that remain slow and unreliable. The former describes a high value route privileging velocity and exclusivity, while the latter connotes delays, frustration and a devaluing of public movement (Cresswell, 2010, p. 25). The fifth aspect of mobility concerns its affective properties, or the ways different forms of mobility feel. Cresswell cites the example of international air travel and the differences between first class travel and economy or cabin class. The "luxury and pampering" of first class travel obviously differs in social, material and affective ways from the "cramped, uncomfortable" realities of economy class (Cresswell, 2010, p. 25). It follows that each space confers a distinctive affective atmosphere. Finally, Cresswell (2010) argues for the importance of assessing the ways mobilities stop, and the various frictions that shape the pace of mobility. Friction concerns the circumstances in which mobility ends, whether by choice or compulsion, and the meanings associated with this cessation.

Our second conceptual point of reference concerns recent geographical interest in affective atmospheres. In an influential contribution, Ben Anderson (2009, p. 80) argues that affective atmospheres "bear a characteristic spatial form - diffusion within a sphere [...] generated by bodies - of multiple types - affecting one another as some form of 'envelopment' is produced". Consistent with the Deleuzian account of affect that informs much of Anderson's analysis, affective atmospheres may be said to capture a store of action-potential (enacted within a 'form of envelopment') that mediates the dispositions and agencies potentially enactable in these spaces (see also Duff, 2010, p. 884-86). This mediation entails a specific manifestation of a body's "power of acting" (Deleuze, 1988, p. 50). Accordingly, affective atmospheres conjure a range of distinctive feeling states, while also mediating a body's willingness or capacity to act in response to those states. David Bissell (2010) provides a 
number of additional insights into affective atmospheres, and the ways they are produced, encountered and transformed in spaces of mobility. Bissell's recent work examines the ways affective atmospheres inspire, suggest or provoke specific kinds of embodied experience in spaces of mobility. For example, in a study of "passenger mobilities" on the "East Coast" rail-line between London and Edinburgh, Bissell (2010, p. 271-72) identifies various "structures of feeling" as they are encountered and transformed in the carriages, train stations and public spaces that constitute this rail-line. These structures of feeling comprise distinctive affective atmospheres that "prime" bodies to act in certain ways (Bissell, 2010, p. 270). To clarify this process of priming, Bissell (2010, p. 76) points to the social relations and "object materialities" that characterise first class travel on the East Coast line, and how they prime travellers to prioritise work rather than leisure or rest. This priming assumes a kind of "imitative contagion" (Bissell, 2010, p. 274) as travellers board the first class carriages and encounter others in the midst of productivity, leaving them more inclined to follow suit. Bissell next describes a very different atmosphere aboard the train on a typical Friday evening. This "energetic" and "expectant" (Bissell, 2010, p. 275-76) atmosphere primes passengers for relaxation at the end of the working work. Such an atmosphere may, however, be interrupted with any delay in transit, particularly in instances where the cause of the delay is unknown such that its length becomes unpredictable. On such occasions, Friday evening's buoyant atmosphere quickly gives way to piqued frustration or annoyance. These affects are transmitted from body to body, intensifying as the delays extend (Bissell, 2010, p. 275).

Of course, not all bodies are affected in the same way by these delays, or by the more positive atmospheres typical of rail journeys at the end of the working week. Indeed, the point is not that affective atmospheres dictate conduct in spaces of mobility, only that these atmospheres make particular kinds of embodied experience more or less likely. This potential derives from the social or collective aspects of mobility and the spaces it constitutes. Bissell (2010, p. 276) argues that the key to understanding the affective atmospheres that shape the spatial and temporal experience of mobility is the "intense coming together of people and things in close proximity". This proximity generates diverse affective responses yet these responses are more than simple feeling states whether positive (joyous) or negative (vexing) (see Deleuze, 1988). Consistent with Anderson's (2009) analysis introduced above, 
Bissell (2010) argues that affective atmospheres of spaces of mobility yield a social and performative hue that primes individuals to act in different ways. Contained within a 'form of envelopment' (Anderson, 2009) these atmospheres are comprised in and of affects in their circulation, as they move through bodies, acting on them by transforming what they are capable of doing or being (Duff 2014, p 41-45). Less clear, however, is how these atmospheres are constituted, how they intensify or dissipate within their space of envelopment over time, and how the priming effect described by Bissell differentially impacts bodies as they move. The present study addressed these questions by examining affective atmospheres in spaces of mobility within Melbourne's NTE, and their role in the incidence of alcohol related problems.

\section{Mobilities in Melbourne's Night-time Economy}

The study was designed to explore the place of alcohol, leisure and sociality in the lives of young adults living in contrasting urban settings in Melbourne. Interviews were conducted in 2012 with 60 young adults aged between 18-24 years, involving equal numbers of males and females. Ethics approval for the research was granted by Human Research Ethics Committees at the University of Melbourne and Curtin University. Participants were recruited from two local government areas (LGAs) within greater Melbourne; the outer-suburban LGA of Hume and the inner-city LGA of Yarra. Hume stretches from the north-western deindustrialising suburbs of Broadmeadows and Gladstone Park, where social disadvantage is acute, to Sunbury, a small and less impoverished satellite town 34 kilometres from Melbourne's CBD. The second LGA, Yarra, abuts Melbourne's CBD and contains several entertainment precincts. While Yarra is serviced by a large number of bus, tram and rail services, public transport options in the City of Hume are more limited, particularly outside peak travel times. Prospective participants were recruited in each LGA via local tertiary institutions, placing flyers in shop windows, though welfare agencies and word of mouth. The majority of participants $(\mathrm{N}=44)$ reported to be studying either full or part-time; two-thirds were employed full or part time and six participants were neither studying nor working. Seventeen participants reported being born overseas and 19 spoke another language in addition to English. Slightly more participants from the Hume LGA reported no involvement in either study or work than the Yarra participants. Otherwise, demographic characteristics were broadly consistent for study participants recruited in each of the two LGAs. 
Participants were offered the choice of completing interviews on their own $(\mathrm{N}=35)$, or in groups with one $(\mathrm{N}=16)$ or two friends $(\mathrm{N}=9)$. Interviews were semi-structured to encourage participants to share accounts of a recent night out in Melbourne. Interviewers probed how people travelled to entertainment precincts; what attracted them to these places; what they drank while they were out; how they returned home; and whether they encountered conflict or other trouble during the night. All research interviews were recorded, transcribed and then coded using the qualitative software package NVivo. This enabled recurrent data analysis as research themes were identified and assessed relative to our research aims (Clarke, 2005, p. 190-202).

Our interest in the affective dimensions of mobility in Melbourne's NTE presented a series of analytical challenges. The tensions between 'representational' research methods, such as the ones employed in the present study, and a concern for 'nonrepresentational' aspects of everyday life, including affect, practice and movement, are a key focus of recent debates in human geography (see Anderson \& Harrison, 2010 for a review). One significant problem concerns the identification of a means of 'capturing' affect, of becoming sensitive to its durational resonances in encounters between bodies, human and non-human, without reducing it to a rhetorical trope, or worse, sentimental cliché (Duff, 2014, p. 35-45). Inspired by J.D. Dewsbury's (2009, p. 321-24) seven injunctions for the conduct of "affect-based" qualitative research, and Sarah Pink's (2009) invitation to a "sensory ethnography", interviews were analysed with a sensitivity to the affective traces of bodies encountering one another on the move. Certainly, we were interested in participant reports of the atmospherics of spaces of mobility in Melbourne's NTE, yet we were equally sensitive to the affective modulations that the very recall of these atmospheres engendered for our participants. Along with Pink (2009), we treated the bodies of our participants (and our own embodied experience as social researchers) as important vectors of these modulations. This involved close attention to the affective dispositions exhibited and described by participants in the course of their interviews. Equally, it involved sustained interest in encounters between bodies, human and nonhuman, as they were described throughout the interviews. We do not mean to suggest that we succeeded in unraveling the varied affective threads conjured in these interviews, although by concentrating on the "nervous energies, amplitudes and thresholds" (Dewsbury, 2009, p. 327) enacted by our participants, we became more sensitive to 
the affective resonances they suggested or revealed. This course provided a means of partially capturing the affective atmospheres of select spaces of mobility in Melbourne, as they were encountered and enacted on a night out drinking in the city. Two aspects of these encounters are relevant to the concerns of this paper: the role of mobilities in shaping plans and drinking events in the NTE; and the affective atmospheres of what may be described as spaces of mobility in Melbourne's NTE. As our analysis indicates, each aspect transforms the embodied and affective capacities of individuals and groups as they move about the NTE drinking and socializing. We discuss various instances of this capacitation in the sections below.

\section{Going Out, Getting About in Melbourne}

Interviews canvassed a range of topics relating to mobility in Melbourne's NTE, including the means by which participants travelled to and from licensed premises on a recent night out, attitudes regarding different modes of transport, and participant experiences within spaces of mobility. What emerged very clearly in these interviews was the sense that experiences of mobility are central to the spatial and temporal organisation of a night out drinking in Melbourne. Even among participants with a driving license and access to a vehicle, driving was found to be unpopular because of the way it restricted their alcohol consumption. Many of these participants acknowledged Victoria's strict drink-driving laws and the fact that any breach of these laws risked the suspension of their license. While traveling to and from venues in a friend's car was said to be ideal, this was reportedly rare given most drivers' reluctance to forego drinking for the night, along with the challenges of finding safe and affordable parking. Hence, participants mostly relied on public transport including trains, trams, buses and taxis, with many inner-city participants also describing cycling or walking to and from drinking venues. Discussions about how to get to, between, and home from venues was thus said to be an important feature of drinking in the city at night. For example, Parvani ${ }^{1}$ (F/24/Hume) spoke of considering friends' transportation preferences when identifying a venue for everyone to meet at:

It depends who wants to come out, and what's convenient for everyone because, obviously everyone lives in different areas and it depends on the travel, if they have a car, if they're coming by train you know. We usually stick to the city because that's central, and most of my friends work there.

\footnotetext{
1 Participants' real names have been changed to preserve their anonymity in the presentation of findings.
} 
It was also common for participants to describe how public transport schedules tended to shape the course of an evening out. Of special significance was the gap in the availability of public transport between the last service of the night (typically around $1 \mathrm{am}$ ) and the resumption of services at around $5 \mathrm{am}$. With limited disposable income, most participants were reluctant (or unable) to take a taxi home and so most spoke of the need to remain conscious of the scheduling of the last train, tram or bus so as to avoid an expensive taxi fare, or a long wait in the city. The widely reported desire to avoid a long wait for transport late at night provides a useful indication of the ways mobilities modulate the atmospherics of Melbourne's NTE. Bound to the 'routes' and 'rhythms' (Cresswell, 2010) of Melbourne's public transport network, many participants spoke of the ways mobility (and immobility) could suddenly transform the affective tone of a night out. Examples include instances described by Hume participants in which a missed train resulted in an expensive taxi fare home, and a mood of frustration and anxiety given this cost. Others described more uplifting moments involving unexpected offers of a car ride home with a friend, or arriving at a tram stop after leaving a venue to find the desired tram arriving only moments later. Even so, reliance on public transport involved unique frustrations as Naresh (M/23/Yarra) explained:

I go to a lot of house parties and usually I catch public transport because I'm obviously drunk so I don't wanna drive. But if I have to catch public transport then I have to finish the night before the trains or trams stop. And you know sometimes I'll leave from house parties, I'm the one who actually leaves pretty much an hour or an hour and a half before the party finishes because I have to catch the tram or a train home.

Naresh's report further alludes to the role of 'speed', 'routes' and 'rhythms' (Cresswell, 2010) in coordinating mobilities in Melbourne's NTE. Yet it also highlights how the rhythms imposed by Melbourne's rail network shape the affective experience of mobility in and around the NTE. Indeed, much of Naresh's frustration at the need to regularly leave parties early in order to catch a train home 'spilled over' (Dewsbury, 2010) into his recounting of his mobility experiences during his interview. Jamie (M/21/Yarra) also noted how routes and rhythms impart distinctive affective atmospheres as one moves about the city at night;

If I go to a house party in say Point Cook and I have to catch a taxi then it'll be around ninety, hundred bucks. I don't wanna pay that much travelling so I prefer to catch trains. Usually l'll ask one of my friends to drop me at the 
station if the station is nearby and I'll catch the train. If I plan it all out then I usually take the last train to save money. But it normally means leaving early.

A number of the Yarra participants cited similar challenges, in addition to the cost of public transport, when describing their preference for walking or cycling at night. Even here though, the need to negotiate routes, traffic, timing, safety and the movement of friends betrays the centrality of mobility to the spatial and corporeal atmospherics of a night out drinking in Melbourne. In describing the experience of walking or cycling, many Yarra participants emphasised the importance of managing alcohol consumption, safety and the selection of routes. Polly (F/23/Yarra) noted,

It's sort of easier just to all ride bikes. So if we're gonna stay at someone's house and not go out then I usually ride my bike over. It's way safer. Like drinking and riding home from the city is far more dangerous than riding ten minutes around here in Fitzroy or Northcote with the traffic. And I guess if you've had a few drinks as well riding from the city just seems a lot worse.

Emma (F/21/Yarra) mentioned the same factors concerning safety, convenience and amenity in deciding whether or not to walk:

Often I just walk there and home again. Cos often I am going out with my boyfriend and he lives in this area too so we can just walk there and then we're able to walk home. It's a lot safer I think that way too. But I tend not to go out if I know I have to catch a taxi or like if I can't just walk and I have to tram it. Like cos early, like 10:30's kind of okay to catch a tram, like still reasonable, but after that time things can get a bit dodgy.

Emma's last remark crystallises an observation made by nearly all participants regarding the atmospherics of spaces of mobility in Melbourne's NTE. Convenience and safety were key issues for almost all participants, with many alluding to how perceptions of safety and convenience were influenced by the affective atmospheres encountered while on the move aboard trains, trams, buses, taxis, walking and/or cycling (see also Middleton, 2011). We would add that these atmospheres reflect the dynamics of mobility described by Cresswell and Bissell - particularly the importance of 'rhythm', 'route', 'experience' and 'friction' - in ways that begin to indicate how affective atmospheres are generated, transformed, resisted or embodied in spaces of mobility. Yet these reports also allude to the ways spaces of mobility mediate the affective capacities of bodies as they move. In a very literal sense, mobilities transform a body's capacity for speed (or slowness), just as they mediate a body's capacity for positive, joyous or enabling encounters (and their obverse) while on the move (Duff 2014, p 35-38). Greater understanding of these processes is crucial for 
advancing our interest in assessing how affective atmospheres mediate alcohol related problems in the NTE. It is equally central to the identification of novel social, affective and material responses to these problems (Shaw, 2014) Our analysis indicates that affective atmospheres mediate drinking and drunkenness in Melbourne's NTE by 'priming' travellers for different practices or behaviours in spaces of mobility Yet our analysis also highlights the need for greater attention to the (co)constitution of affective atmospheres in encounters between bodies (human and nonhuman) as they move.

\section{Atmospheres of Mobility; Waiting, Moving and Priming}

We have already noted how vital public transport schedules are to participant's experience of mobility in Melbourne's NTE. Yet we also found that waiting for the right public transport service - the one that was going to take one closest to one's preferred destination in the shortest possible time - was an inevitable part of a night out drinking for many participants. Waiting at the station, tram stop or taxi queue involved varied affective atmospheres, which were often said to "colour" the rest of the night. Describing a recent night out, Sienna (F/20/Hume) recounted how;

The worst thing is when you just miss a train and like a taxi is too much or there aren't any around. Last weekend, my friend's $21^{\text {st }}$, we went to catch a train and we had just missed one so we had to wait like twenty-eight minutes for the next one. That was probably the worst part of the night. Well the taxi later was pretty annoying too. Getting the taxi on a Saturday night takes a long time. Yeah, being cold, waiting for trains and taxis, it's not much fun.

Hayden (M/18/Hume) added that these kinds of frustrations often compound later in the evening as individuals struggle to organise the most convenient ways home:

It's harder to get a cab back home than to get in [to the city], it's easy to get in but harder to get out. So you just end up waiting, like you just can't ever go home when you want to. You've just gotta wait you know what I mean. So you just end up sitting around for hours trying to get a cab or waiting til the first train comes or something. It gets pretty boring some times.

Spaces of mobility in Melbourne's NTE were thus found to include spaces of stillness or immobility consistent with both Cresswell's (2010, p. 18) and Bissell's (2010, p. 271) accounts of mobility reviewed above. Waiting in taxi queues, at train stations or at tram stops often yielded a range of negative affective atmospheres, redolent of boredom, fatigue and frustration. More significantly, our analysis suggests that these atmospheres, and the spaces they project, are routinely implicated in the experience 
of alcohol related problems, such as fights and arguments in Melbourne's NTE. Without always observing the conceptual logic of affective atmospheres, Honey (F/24/Yarra) described a mood of frustration and boredom waiting for transport in the city, and the ways this mood seemed to 'prime' some individuals for conflict.

I think a lot of the time people are just so frustrated with waiting, it's just boring. Like with the taxi ranks, you could be waiting there for hours. It's a long time. And I think, especially when people have been drinking and they're starting to get tired, they're sick of being out and they're sick of being in the cold, or if they've been kicked out of somewhere for being too drunk and they wanna get home, then yeah, they can get frustrated. And I think Australians are a bit racist too, and the taxi drivers are not white skinned you know. And so people get like this, you know, they're sick of being out and they're sick of being in the cold, and that's when they're like to the drivers "why weren't you here earlier, what's your problem", you know, all that stuff. So I think people who might be more polite usually, when they're drunk and they're cold and they're tired of waiting and they wanna be at home, they can be rude.

Honey's observations speak to the constituent features of affective atmospheres and the ways they are enacted in encounters between (intoxicated) bodies in spaces of mobility. Consider the range of bodies, affects and entities described by Honey: taxi ranks where too many bodies encounter too few taxis; climatic conditions and their effects/affects on drunken bodies; security practices in local venues and their impact on the atmospherics of spaces of mobility at night; and, finally, attitudes regarding race and class and the conflict generated in encounters between bodies marked by these distinctions. In each case, varied affective dispositions emerge in the proximity of bodies. As a result, people "who might be more polite usually" are primed for particular kinds of (racist) behaviour by the atmospheres they encounter. Individuals also contribute their own affective valence to these atmospheres, just as nonhuman bodies (alcohol, spaces of transit, infrastructure, taxis, ideas of race and class) impart further affective hues. Honey's recollections thus describe a crowd of bodies producing or transmitting atmosphere in the encounters immanent to this crowd.

Rima (F/21/Hume) observed an even more direct link between the affective atmospheres common to spaces of mobility (and immobility) in Melbourne's NTE and the experience of drinking in the city at night. She recounted,

Like either you just run out of money or there are no trains so you just have to wait. Normally I just wait at the station, or if I'm not there waiting I'm out looking for another place to drink cos there's usually places that are open 'til seven or eight in the morning like recovery bars and things. But like the people in there, they're all seedy cos it's like really, really late, you should be 
at home by now you know. They're just really creepy people. But you don't think about it cos you're off your face [laughter].

Other participants described varying affective atmospheres while on the move, although some rather striking differences emerged between the reports offered by participants in Yarra and Hume. As we have noted, Yarra participants tended to report walking, cycling or "tramming" about the inner-city, whereas participants from Hume typically experienced longer journeys on the train or in taxis. While some Yarra participants expressed reservations about travelling on the tram later at night, most reported "pleasant", "fast" or "easy" trips walking, cycling or on the tram. Summing up the experiences of many Yarra participants, Elke (F/24/Yarra) observed

It's really easy round here, lots of places to go and most of us live around the inner-city so we're always walking and riding to things, bands and parties. I always try to plan it out a little bit but yeah I try to often just take my bike and not drink too much and then I can still just go home whenever I want to. And if it's around the area then I can just walk home, which is really nice as well.

Another Yarra participant Steven (M/22/Yarra) made a similar observation about the kinds of affective atmospheres common to cycling home "after a big night":

That's one of the advantages of cycling isn't it? If you're not too drunk, I guess. Like it's easy to get home and especially in the summer time it can be great fun with loads of other people out riding too, it's just a good fun vibe.

Hume participants, on the other hand, tended to report the experience of very different affective atmospheres, particularly on the journey home after a night out. With limited options, given the cost of taxis and the absence of rail connections for part of the evening, most Hume participants reported either waiting for the train services to resume or taking the Nightrider bus, which was almost universally reviled for its negative atmosphere. Participants commonly described an atmosphere of aggression, boredom and frustration on board the Nightrider bus, with passengers often drunk and aggravated with delays and the length of the trip home. Fights and other problems were also reported to be common. Amy (F/19/Hume) noted that,

We have to use the Nightrider [bus] cos we don't normally have any other options unless we wait for the train. But the bus is just so dodgy. Like the last time, my mate came over from Adelaide, and like well I didn't get drunk, oh I got tipsy, probably not that bad. But my friend got really drunk and we had to travel back on the Nightrider and it was really scary cos some kid got beaten up for no reason, and I was scared my friend was gonna say something and we'd get bashed too. So I was just trying to keep him distracted when I wasn't dozing off. And then I think he started falling asleep and we got home at like six in the morning because it was the only way to get home. Pretty crap really. 
Bella (F/21/Hume) spoke of how she tried to avoid the bus, even though this wasn't always possible. She shared Amy's assessment of the atmosphere aboard the bus;

You'd do anything to not go on the Nightrider, it's so awful. It stops at every stop on the way so it takes ten times longer than anything else. You've got absolutely off their face [intoxicated] people on the bus. Like the amount of times we've been on it and there's been punch-ons [violence] and there's been people kicked off. Especially for a female, it's not a nice place to put yourself in. So you'd rather work something out, plan it a bit. I pretty much just say to all my friends "I'm not gonna go unless l've got a guaranteed lift home cos I'm not getting stuck in the city and I'm not going to put myself in a situation which isn't pleasant".

Carly (F/23/Hume) explicitly pointed to the ways intoxication and fatigue, mixed with the fact that home was a long way away, seemed to prime passengers for conflict.

It takes two to three hours on the Nightrider so you don't get home to like 6 . So it's a problem cos when we leave you feel a sense of urgency to go home, usually you know we're very intoxicated and we just wanna be home now. And the bus is scary, sometimes we feel very unsafe because there's only probably four girls and we're by ourselves and you can imagine the characters that are usually on the bus too. And we're waiting for this bus that takes three hours to get home, we don't know what time we'll get home and it makes me very anxious sometimes. And everyone's just tired and grumpy and that's when you know the problems start. But that's how we have to get home.

Despite endorsing something like the 'priming' effect central to Bissell's (2010) discussion of affective atmospheres, Carly also reveals how these atmospheres are modulated in encounters between bodies in spaces of mobility. More directly, Carly's account confirms the significance of affective dispositions in her own peer group, and how a shared anticipation of frustration, delays, fear, sexual harassment and/or conflict impinges on the atmospheres encountered on the bus. Carly's report thus indicates how bodies both encounter, and further inflect, affective atmospheres while on the move, pointing to the ways atmospheres are (co)constituted in encounters.

\section{Discussion}

The accounts reported above reveal the importance of spaces of mobility in Melbourne's NTE, and their role in the spatial and temporal organisation of a night out drinking in the city. Unsurprisingly, participants from Melbourne's periurban fringe reported spending significant periods of time on the move traveling to, from and between venues. Yet even youth from the inner-city acknowledged the importance of mobility to the experience of a "good night out". Indeed, many participants reported 
spending as much time on the move on a given night as they did attending bars and clubs. It is curious, therefore, that spaces of mobility have been so neglected in recent literature on the NTE, particularly when compared to the wealth of data concerning the affective and embodied experience of other spaces in the NTE, including bars, clubs and streetscapes (Jayne et al., 2010; Shaw, 2014). Hence, the significance of the present study lies in the attention it draws to the experience of mobility in Melbourne's NTE. More directly, we conclude that the affective atmospheres young people encounter while on the move in Melbourne's NTE are an integral part of the experience of drinking in the city at night. As we have argued throughout the paper, these atmospheres are important not only for what they reveal about the feel and experience of mobility in Melbourne's NTE, but also for the ways they prime individuals for certain behaviours. This 'priming effect' offers valuable insights into the incidence of alcohol related problems in the NTE, while further endorsing Jayne and colleagues call for greater sensitivity to the affective, embodied and performative experience of drinking in the city at night (see Jayne et al., 2008).

It is notable that many of the affective atmospheres described by our participants were portrayed in negative terms. Examples include participants who described "boring" or "frustrating" waits for the resumption of the first train in the morning; others who described uncomfortable delays in long taxi queues; along with "impatient" waits for a specific tram or train to take participants to their preferred destination. The experience of "boredom", "frustration" and fatigue were common affective attributes of many participants' reports of transit. Other scholars have offered similar reports of boredom, fatigue and disappointment in the NTE (Binney et al, 2007; Jayne et al, 2012, p. 218-220; Shaw 2014, p. 89-91), and a reminder that the affective and embodied experience of drinking in the city at night does not always result in pleasure, conviviality or excitement. While in our own study a number of inner-city participants described more positive affective experiences walking or cycling home, most participants reported travelling home tired after a long night, in varying degrees of intoxication. These journeys were commonly associated with a range of negative atmospheres, with a small number of participants describing atmospheres of anxiety or fear, amid concerns regarding their safety. Our analysis indicates that these negative atmospheres potentially prime travellers for a range of antisocial behaviours. For example, many participants described instances waiting 
for transport, or while on the move, in which the experience of intoxication and fatigue, in an atmosphere of frustration or anxiety, combined to produce conflict. The Nightrider bus is certainly the most striking example of this kind of affective priming, though participants noted similar atmospheres in other spaces of mobility too.

However, our data also suggest something of the way affective atmospheres are (co)constituted in encounters between bodies in spaces of mobility. While participants certainly described instances of 'entering into' particular kinds of atmosphere, our data also reveal much of ways these atmospheres are inflected, transformed, resisted or compounded in the affectivity of bodies in their encounters. Examples include Sienna's frustration at missing a train on her way to a friend's birthday celebration, and her keen awareness of missing part of the enjoyment of the party. Or consider Honey's evocative account of the racism she observed waiting for a taxi home, and the various factors, conditions and practices that contributed to the formation of affective atmospheres in this space. The most compelling examples include Amy's, Bella's and Carly's recollections of trips home on the Nightrider bus, and the ways their own apprehensions and frustrations collided with the moods prevailing on the bus. Atmospheres of fatigue and irritation were widely reported aboard the bus, along with more rambunctious or festive ones, although it is striking that Amy, Bella and Carly each acknowledged something of their own contributions to the valence of these atmospheres. Their reports also allude to the significance of the nonhuman forces cited in Cresswell's and Bissell's accounts of the dynamics of mobility. Indeed, for most of our participants, encounters with the means of mobility, including trains, trams and cars/taxis, were found to be pivotal to the experience of affective atmospheres. Encounters with spaces of immobility while waiting for transportation added their own distinctive 'object materialities' to the constitution of these atmospheres. In each case, one finds an assemblage of bodies, materials, moods, practices and technologies converging (or encountering one another) in the creation, modulation and contestation of affective atmospheres in spaces of mobility.

And so, while we partially endorse Bissell's description of the priming effects of affective atmospheres - as we noted in relation to some participants' experience of alcohol related problems in the city - it is equally important that attention be paid to how these atmospherics are modulated, compounded or resisted in encounters 
between bodies in transit. Moreover, something akin to Cresswell's (2010) politics of mobility is evoked in this process of atmospheric (co)constitution. For example, the key difference in the mobility narratives offered by participants from Hume and Yarra concerned the divergent affective atmospheres encountered while on the move, and the ways these atmospheres were said to shape the experience of mobility in Melbourne's NTE. Yarra participants were just as likely as the Hume participants to report venturing home in varying states of intoxication. The difference was that Yarra participants were significantly less likely to face a long journey home in which a collective mood of frustration, fatigue, boredom and/or anxiety occasionally manifested in arguments, violence or discrimination. These atmospheres prime individuals for conflict. Yet the constitution of these atmospheres also reflects structural inequalities in access to the means of mobility in Melbourne. Greater acknowledgement of the social, political, economic and affective dimensions of mobility exemplifies Cresswell's (2010) call for a politics of mobility. This politics may also yield novel strategies for reducing alcohol related problems in the city at night.

\section{Conclusions}

At the heart of Cresswell's (2010, p. 21) assessment of the politics of mobility is the observation that "mobility is a resource that is differentially accessed". Understood in terms of motive force, speed, rhythm, route, experience and friction, both the opportunity and the means of initiating and maintaining mobility reflect important social, economic and political distinctions between groups, classes or entities. It follows that the capacity to move about in Melbourne's NTE is itself indicative of differences in power and status, or access to resources. Robert Shaw (2014), Gordon Waitt and Anna De Jong (2014) have reported similar findings, with each author describing how power and status are differentially embodied in spaces of mobility and consumption in the NTE. Echoing these reports, participants from Yarra reported significant advantages compared to participants from Hume in terms of the range, amenity and reliability of transport options available to them. Including diverse tram, bus and rail services, a large number of competing taxi operators, and of course the capacity to walk or cycle should they choose to, participants from Yarra enjoyed greater choice in their mobilities, at greater speed, in more amenable rhythms and routes, with less friction than participants from Hume, to employ Cresswell's (2010, p. 22-6) analytical vocabulary. The atmospheres encountered 
while on the move differed in significant ways too, with participants from Yarra typically reporting more positive (or joyous) experiences than the Hume participants.

Paying due attention to these atmospheric distinctions takes on political significance to the extent that they trouble popular and scholarly assessments of the causes of problems in the NTE, such as violence, accidents, fights, intoxication and public nuisance (see Jayne et al., 2011; Shaw, 2014; Binnie et al., 2007). Much of the contemporary literature on these problems treats them as a function of irresponsible alcohol consumption, a liberal licensing environment, and/or aggressive competition between venues in the sale and promotion of alcohol (Babor et al., 2010). Hence, problems in the NTE are commonly attributed to the permissive attitudes of irresponsible consumers, and a laissez-faire policy environment which promotes commerce at the expense of public health. Of course, much existing evidence suggests that consumer education and stricter licensing arrangements may reduce problems in the NTE, yet the literature in which these kinds of claims emerge says very little about the actual experience of drinking in the city at night (Jayne et al., 2010). Greater attention to the diversity of drinking experiences in the NTE should enable more sophisticated assessments of the causes of problems in this economy.

The evidence canvassed above suggests that the affective atmospheres encountered, sustained and transformed in spaces of mobility play some role in the incidence of alcohol related problems in Melbourne's NTE. It is not just a question of how much young people drink at night, but how they move about in the NTE, and the kinds of experiences they have while on the move. As such, the political issues raised by Cresswell regarding the speed, feel, routes and rhythms of mobility are critical to ongoing discussions regarding the most effective ways of reducing alcohol related problems in the NTE. Many scholars have noted the need for more frequent and reliable public transport to ameliorate problems in the NTE, particularly later in the evening (MacLean \& Moore, 2014). While our study endorses this conclusion, we would add that attention ought to be extended to the motives, speeds, rhythms, routes and atmospheres that characterise mobility in the city at night. After all, finding ways to manipulate affective atmospheres in spaces of mobility in the NTE may end up being one of the most effective ways of reducing problems in the city at night. The means of such manipulation are the subject of a bourgeoning research 
literature (Anderson, 2009; Bissell, 2010; Shaw, 2014). Drawing on this literature, future research should prioritise the identification of a means of dissipating atmospheres of frustration, boredom and fatigue in the cultivation of a collective space of joy in mobility in the NTE (see Duff, 2014; Shaw, 2014 for a review).

Our contention that renewed sensitivity to the embodied experience of drinking in the city may avail new strategies for addressing alcohol related problems in the NTE reiterates the value of Jayne and colleagues' (2008) call for an affective geography of drinking and drunkenness. While any focus on affect presents methodological and logistical challenges (Anderson 2009), it offers the prospect of transcending cognitive and/or behaviourist approaches to the study of alcohol related problems in the NTE, which tend to emphasise the importance of individual responsibility by relying on narrow linear understandings of the etiology of these problems (Jayne et al, 2008, p. 551-553; MacLean and Moore 2014, p. 381-83). By following the 'affective turn' (Anderson 2009), studies of alcohol related problems in the NTE must necessarily adopt more complex and emergent notions of causality, alert to the range of human and nonhuman forces active in the social, affective and performative experience of drinking in the city (Duff 2014, p. 146-148). The work of Jayne and colleagues (2012), Shaw (2014), Maclean and Moore (2014), Waitt and colleagues (2011) and Waitt and De Jong (2014) provide examples of qualitative research designs equal to this challenge, along with important insights into the social, affective and material forces active in the production (and moderation) of alcohol related problems in the NTE. The present paper has added to these insights by focussing on the atmospherics of spaces of mobilities. Taken together, this emerging literature points to novel social, performative and affective responses to the problems associated with drinking in the city (see Jayne et al, 2011). Mainly, it suggests that not all problems in the NTE may be attributed to alcohol, with the corollary that other bodies, affects and forces ought to be the focus of novel responses to these problems.

\section{Acknowledgements}

We thank Sarah MacLean, Mutsumi Karasaki and Christine Siokou for conducting the interviews on which this article is based, and Sarah MacLean for coding the interview transcripts. We are grateful for funding from the Australian Research Council (LP 100100017), VicHealth and the Victorian Department of Health. Hume 
City Council, Yarra City Council and the Municipal Association of Victoria each made in-kind contributions to the study. The National Drug Research Institute at Curtin University is supported by funding from the Australian Government under the Substance Misuse Prevention and Service Improvement Grants Fund.

\section{References}

Anderson, B. (2009). Affective Atmospheres. Emotion, Space \& Society. 2(2):77-81.

Babor, T., Caetano, R., Casswell, S., Edwards, G., Giesbrecht, N., Graham, K., et al. (2010). Alcohol: No ordinary commodity. Oxford: Oxford University Press.

Binnie, J., Edensor, T., Holloway, J., Millington, S., \& Young, C. (2007). Mundane mobilities, banal travels: Editorial. Social \& Cultural Geography, 8(2), 165-174.

Bissell, D. (2010). Passenger mobilities: affective atmospheres and the sociality of public transport. Environment \& planning D: Society \& Space. 28(2):270-289.

Clarke, A. (2005). Situational Analysis. Thousand Oaks, CA: Sage.

Cresswell, T. (2010). Towards a politics of mobility. Environment and planning D: Society and space. 28(1):17-31.

Deleuze, G. (1988) Spinoza: Practical Philosophy. San Francisco: City Lights.

Dewsbury, J. D. (2010). Performative, non-representational, and affect-based research: seven injunctions. The SAGE Handbook of Qualitative Geography. London: SAGE Publications. $\mathrm{Pp}, 321-334$.

Duff, C. (2010). 'On the Role of Affect and Practice in the Production of Place'. Environment and Planning D: Space and Society. 28(5):881-895.

Duff, C. (2014). Assemblages of Health: Deleuze's Empiricism and the Ethology of Life. Amsterdam: Springer International.

Eldridge, A., \& M. Roberts. (2008). A comfortable night out? Alcohol, drunkenness and inclusive town centres. Area. 40(3):365-374.

Hubbard, P. (2007). The Geographies of 'Going Out': Emotion and Embodiment in the Evening Economy. In J. Davidson, L. Bondi and M. Smith (eds.). Emotional Geographies. Hampshire: Ashgate.

Jayne, M., Holloway, S., \& G. Valentine. (2006). Drunk and disorderly: alcohol, urban life and public space. Progress in Human Geography. 30(4):451-468.

Jayne, M., Valentine, G., \& S. Holloway. (2008). Geographies of alcohol, drinking and drunkenness: a review of progress. Progress in Human Geography, 32(2), 247-263.

Jayne, M., Valentine, G., \& S. Holloway. (2010). Emotional, embodied and affective geographies of alcohol, drinking and drunkenness. Transactions of the Institute of British Geographers. 35(4):540-554.

Jayne, M., Valentine, G., \& Holloway, S. (2011). Alcohol, Drinking, Drunkeness:(dis) orderly Spaces. London: Ashgate Publishing.

Jayne, M., Gibson, C., Waitt, G., \& Valentine, G. (2012). Drunken mobilities: Backpackers, alcohol ,'doing place'. Tourist Studies. 12(3):211-231.

MacLean, S. \& Moore, D. (2014). 'Hyped up': Assemblages of alcohol, excitement and violence for outer-suburban young adults in the inner city at night. International Journal of Drug Policy 25(3): 378-385.

Middleton, J. (2011). Walking in the city: The geographies of everyday pedestrian practices. Geography Compass, 5(2), 90-105. 
Roberts, M. (2006). From 'creative city'to 'no-go areas'-the expansion of the nighttime economy in British town and city centres. Cities, 23(5), 331-338.

Roberts, M., \& A. Eldridge. (2009). Planning the night-time city. London: Routledge.

Shaw, R. (2014). Beyond night-time economy: Affective atmospheres of the urban night. Geoforum, 51, 87-95.

Waitt, G. \& de Jong, A. (2014) Embodied geographies of alcohol and the weekend in the Bega Valley, New South Wales. Leisure Studies 33(2):116-132.

Waitt, G., Jessop, L., \& Gorman-Murray, A. (2011). 'The guys in there just expect to be laid': Embodied and gendered socio-spatial practices of a 'night out'in Wollongong, Australia. Gender, Place and Culture. 18(2): 255-275. 